\title{
Explicitly correlated intermolecular distances and interaction energies of hydrogen bonded complexes
}

\author{
Joseph R. Lane and Henrik G. Kjaergaard ${ }^{\text {a) }}$ \\ Department of Chemistry, University of Otago, P.O. Box 56, Dunedin 9054, New Zealand
}

(Received 29 March 2009; accepted 8 June 2009; published online 16 July 2009)

\begin{abstract}
We have optimized the lowest energy structures and calculated interaction energies for the $\mathrm{H}_{2} \mathrm{O}-\mathrm{H}_{2} \mathrm{O}, \mathrm{H}_{2} \mathrm{O}-\mathrm{H}_{2} \mathrm{~S}, \mathrm{H}_{2} \mathrm{O}-\mathrm{NH}_{3}$, and $\mathrm{H}_{2} \mathrm{O}-\mathrm{PH}_{3}$ dimers with the recently developed explicitly correlated CCSD(T)-F12 methods and the associated VXZ-F12 (where $X=\mathrm{D}, \mathrm{T}, \mathrm{Q}$ ) basis sets. For a given cardinal number, we find that the results obtained with the CCSD(T)-F12 methods are much closer to the $\operatorname{CCSD}(\mathrm{T})$ complete basis set limit than the conventional $\operatorname{CCSD}(\mathrm{T})$ results. In general we find that $\operatorname{CCSD}(\mathrm{T})$-F12 results obtained with the VTZ-F12 basis set are better than the conventional $\operatorname{CCSD}(\mathrm{T})$ results obtained with an aug-cc-pV5Z basis set. We also investigate two ways to reduce the effects of basis set superposition error with conventional $\operatorname{CCSD}(\mathrm{T})$, namely, the popular counterpoise correction and limiting diffuse basis functions to the heavy atoms only. We find that for a given cardinal number, these selectively augmented correlation consistent basis sets yield results that are closer to the complete basis set limit than the corresponding fully augmented basis sets. Furthermore, we find that the difference between standard and counterpoise corrected interaction energies and intermolecular distances is reduced with the selectively augmented basis sets. ㅇ 2009 American Institute of Physics. [DOI: 10.1063/1.3159672]
\end{abstract}

\section{INTRODUCTION}

Weakly bound complexes are recognized as intermediates between strictly gas-phase and condensed-phase species that are important for describing the chemistry of Earth's atmosphere. $^{1-3}$ The formation of complexes can cause changes to the absorption spectra and chemical reactivities of the constituent monomers, which can potentially open up entirely new avenues of chemistry in the atmosphere. ${ }^{4-10}$

In the present work, we investigate the geometries and interaction energies of the monohydrated complexes of water $\left(\mathrm{H}_{2} \mathrm{O}-\mathrm{H}_{2} \mathrm{O}\right)$, hydrogen sulfide $\left(\mathrm{H}_{2} \mathrm{O}-\mathrm{H}_{2} \mathrm{~S}\right)$, ammonia $\left(\mathrm{H}_{2} \mathrm{O}-\mathrm{NH}_{3}\right)$, and phosphine $\left(\mathrm{H}_{2} \mathrm{O}-\mathrm{PH}_{3}\right)$. The water dimer is considered as a prototypical system for hydrogen bonded complexes and has been extensively studied with a variety of theoretical and experimental approaches. We reference here a selection of some of the more recent high level calculations. ${ }^{11-17}$ The water ammonia complex is more strongly bound than water dimer and has prompted a few theoretical investigations. ${ }^{18-23}$ There are only limited calculations for the equivalent second row hydride complexes, $\mathrm{H}_{2} \mathrm{O}-\mathrm{H}_{2} \mathrm{~S}$ and $\mathrm{H}_{2} \mathrm{O}-\mathrm{PH}_{3}{ }^{21,22,24-27}$

We investigate the optimized geometries, harmonic vibrational frequencies, and interaction energies for $\mathrm{H}_{2} \mathrm{O}-\mathrm{H}_{2} \mathrm{O}, \mathrm{H}_{2} \mathrm{O}-\mathrm{H}_{2} \mathrm{~S}, \mathrm{H}_{2} \mathrm{O}-\mathrm{NH}_{3}, \mathrm{H}_{2} \mathrm{O}-\mathrm{PH}_{3}$, and their constituent monomers. The motivation for this research is threefold. First, we intend to test the performance of the recently developed explicitly correlated CCSD(T)-F12 methods using a series of small hydrogen bonded molecular complexes. The four complexes chosen are small enough that conventional $\operatorname{CCSD}(\mathrm{T})$ calculations of benchmark quality

${ }^{a)}$ Electronic mail: henrik@chemistry.otago.ac.nz. can be completed and we use these for comparison. The painfully slow convergence of electron correlation energy with increasing basis set size is one of the great challenges in modern computational chemistry. The explicitly correlated CCSD(T)-F12 methods are claimed to give results using a triple- $\zeta$ basis set that are better than conventional $\operatorname{CCSD}(\mathrm{T})$ with a quintuple- $\zeta$ basis set. ${ }^{28}$ However, it is not clear how well these explicitly correlated methods will describe weak intermolecular interactions and how they are affected by basis set superposition error (BSSE).

Second, it is well established that the inclusion of diffuse basis functions is important for describing van der Waals complexes. ${ }^{29}$ However, it has recently been suggested that the inclusion of diffuse basis functions on the hydrogen atoms of complexes may exacerbate the effects of BSSE when using large correlation consistent basis sets. ${ }^{30}$ We investigate this effect by comparing the results obtained with selectively augmented basis sets to the fully augmented results and to the explicitly correlated results. We also compare our conventional $\operatorname{CCSD}(\mathrm{T})$ results to the results obtained with counterpoise (CP) correction, which is commonly used to alleviate problems with BSSE. ${ }^{14,17,23,31-38}$ While CP correction of correlated wave functions such as MP2 and $\operatorname{CCSD}(\mathrm{T})$ has been theoretically criticized, ${ }^{39-41}$ it is still routinely used with these methods and also appears to work well for HartreeFock and density functional methods. ${ }^{39,42,43}$

Finally, we are also interested in any apparent differences between the $\mathrm{H}_{2} \mathrm{O}-\mathrm{PH}_{3}$ complex and the other complexes considered. Phosphine has been detected in the upper troposphere and it is conjectured that phosphine is less readily incorporated into aerosol than hydrogen sulfide and ammonia. ${ }^{44}$ While not a consummate model, the $\mathrm{H}_{2} \mathrm{O}-\mathrm{PH}_{3}$ 
dimer should be a reasonable first approximation for assessing the mobility of phosphine gas in the atmosphere.

The present investigation serves not only to accurately calculate the structures of $\mathrm{H}_{2} \mathrm{O}-\mathrm{H}_{2} \mathrm{O}, \mathrm{H}_{2} \mathrm{O}-\mathrm{H}_{2} \mathrm{~S}$, $\mathrm{H}_{2} \mathrm{O}-\mathrm{NH}_{3}$, and $\mathrm{H}_{2} \mathrm{O}-\mathrm{PH}_{3}$ but provides interaction energies and intermolecular distances suitable for benchmarking. Weakly bound complexes are challenging systems to describe with electronic structure theory. Our present benchmark results should be useful for estimating error in lower level $a b$ initio methods and for calibrating molecular mechanics and density functional development.

\section{THEORETICAL METHODS}

We have fully optimized the geometries of $\mathrm{H}_{2} \mathrm{O}-\mathrm{H}_{2} \mathrm{O}$, $\mathrm{H}_{2} \mathrm{O}-\mathrm{H}_{2} \mathrm{~S}, \mathrm{H}_{2} \mathrm{O}-\mathrm{NH}_{3}, \mathrm{H}_{2} \mathrm{O}-\mathrm{PH}_{3}$, and their constituent monomers with the coupled cluster singles doubles and perturbative triples $[\mathrm{CCSD}(\mathrm{T})]$ ab initio theory using Dunningtype correlation consistent basis sets. The lowest energy structure of each complex is shown in the supplementary deposit. ${ }^{45}$ With a suitably large basis set, the $\operatorname{CCSD}(\mathrm{T})$ method has been shown to give accurate geometries of small systems that are in excellent agreement with experiment. ${ }^{31,46,47}$ We have used the cc-pVXZ and aug-cc-pVXZ basis sets (where $X=\mathrm{D}, \mathrm{T}, \mathrm{Q}, 5,6)$ for first row elements and the cc-pV $(X+\mathrm{d}) \mathrm{Z}$ and aug-cc-pV $(X+\mathrm{d}) \mathrm{Z}$ basis sets (where $X=\mathrm{D}, \mathrm{T}, \mathrm{Q}, 5,6$ ) for all second row elements. ${ }^{48-50}$ For brevity, we refer to these basis sets as $\mathrm{VXZ}$ and $\mathrm{AVXZ}$ (where $X=\mathrm{D}, \mathrm{T}, \mathrm{Q}, 5,6$ ) whereby it is assumed that second row elements have the additional tight $d$ basis functions. We have also constructed basis sets where only the heavy atoms (i.e., all atoms but hydrogen) are augmented with diffuse basis functions and we refer to these as $\mathrm{A}^{\prime} \mathrm{VXZ}$ (where $\left.X=\mathrm{D}, \mathrm{T}, \mathrm{Q}, 5,6\right){ }^{40}$

We have optimized the geometry of the complexes using both a standard optimization scheme and also a full CP corrected optimization scheme to reduce the effects of BSSE on our optimized geometry. ${ }^{32}$ We have recently shown that this approach gives accurate geometries of monohydrated complexes with an accuracy that is comparable to the precision of most experimentally determined structures. ${ }^{23,33,51}$

We have also optimized the geometries of $\mathrm{H}_{2} \mathrm{O}-\mathrm{H}_{2} \mathrm{O}$, $\mathrm{H}_{2} \mathrm{O}-\mathrm{H}_{2} \mathrm{~S}, \mathrm{H}_{2} \mathrm{O}-\mathrm{NH}_{3}, \mathrm{H}_{2} \mathrm{O}-\mathrm{PH}_{3}$, and their constituent monomers with the newly developed explicitly correlated CCSD(T)-F12 methods as implemented in MOLPRO 2008.1. ${ }^{52,53}$ We have used the VXZ-F12 orbital basis sets (where $X=\mathrm{D}, \mathrm{T}, \mathrm{Q}$ ) of Peterson et al. ${ }^{54}$ that have been specifically optimized for use with explicitly correlated F12 methods. For a given cardinal number, the VXZ-F12 basis sets have been designed to be of similar size to the equivalent aug-cc-pVXZ and aug-cc-pV $(X+d) Z$ basis sets. Density fitting approximations ${ }^{55,56}$ were used in all explicitly correlated calculations using the VXZ/JKFIT (where $X=\mathrm{D}, \mathrm{T}, \mathrm{Q}$ ) and the AVXZ/MP2FIT (where $X=\mathrm{D}, \mathrm{T}, \mathrm{Q}$ ) auxiliary basis sets of Weigend et al. ${ }^{57,58}$ We have used the resolution of the identity (RI) auxiliary basis sets of Yousaf and Peterson ${ }^{59}$ for all RI approximations. The default CCSD-F12 correlation factor $\left[(1 / \beta) e^{-\beta r_{12}}\right.$, where $\left.\beta=1\right]$ was used in all explicitly correlated calculations. Two different approximations are available for solving the CCSD(T)-F12 energies in MOLPRO 2008.1, denoted as CCSD(T)-F12a and CCSD(T)-F12b. Unless specified when we refer to the $\operatorname{CCSD}(\mathrm{T})$-F12 methods we mean both the $\operatorname{CCSD}(\mathrm{T})-\mathrm{F} 12 \mathrm{a}$ and $\operatorname{CCSD}(\mathrm{T})-\mathrm{F} 12 \mathrm{~b}$ methods.

We have extrapolated the $\operatorname{CSSD}(\mathrm{T})$ energies to the complete basis set (CBS) limit with the following two parameter extrapolation for the correlation energy:

$$
E_{X Y}^{\mathrm{corr}}=\frac{X^{3} E_{X}^{\mathrm{corr}}-Y^{3} E_{Y}^{\mathrm{corr}}}{X^{3}-Y^{3}}
$$

where $X$ and $Y$ are the cardinal numbers of the two basis sets and $E_{X}^{\text {corr }}$ and $E_{Y}^{\text {corr }}$ are the corresponding correlation energies. ${ }^{60,61}$ The extrapolated correlation energy $E_{Q 5}^{\text {corr }}$ is added to the HF/AV5Z energy to give an estimate of the CCSD(T)/CBS limit energy. All energies are obtained using a fixed $\operatorname{CCSD}(\mathrm{T}) / \mathrm{AVQZ}, \operatorname{CCSD}(\mathrm{T}) / \mathrm{A}^{\prime} \mathrm{VQZ}$, or $\operatorname{CCSD}(\mathrm{T}) / \mathrm{VQZ}$ optimized geometry.

We estimate the intermolecular distance of $\mathrm{H}_{2} \mathrm{O}-\mathrm{H}_{2} \mathrm{O}$, $\mathrm{H}_{2} \mathrm{O}-\mathrm{H}_{2} \mathrm{~S}, \mathrm{H}_{2} \mathrm{O}-\mathrm{NH}_{3}$, and $\mathrm{H}_{2} \mathrm{O}-\mathrm{PH}_{3}$ at the $\mathrm{CCSD}(\mathrm{T}) / \mathrm{CBS}$ limit by numerically determining the minimum of a CBS intermolecular potential obtained using Eq. (1). The potential used extends from -0.40 to $+0.50 \AA$ in $0.05 \AA$ steps about the equilibrium value of the intermolecular distance. All other geometric parameters are kept fixed.

Intermolecular vibrational modes in complexes are known to be highly anharmonic. We estimate the anharmonic correction to the intermolecular distance by calculating the expectation value of $R_{\mathrm{O} \cdots \mathrm{O}}, R_{\mathrm{O} \cdots \mathrm{S}}, R_{\mathrm{O} \cdots \mathrm{N}}$, and $R_{\mathrm{O} \cdots \mathrm{P}}$ in the vibrational ground state. We use the CCSD(T)/CBS limit intermolecular potential energy curve described above and solve the resulting one-dimensional Schrödinger equation using a finite element method to give the ground state vibrational energy and wave function. ${ }^{62}$ We estimate the reduced mass of the intermolecular stretching vibrational mode by assuming point masses for the $\mathrm{H}_{2} \mathrm{O}, \mathrm{H}_{2} \mathrm{~S}, \mathrm{NH}_{3}$, and $\mathrm{PH}_{3}$ subunits.

We calculate the thermodynamic parameters and the equilibrium constant $\left(k_{\text {eq }}\right)$ for the formation of $\mathrm{H}_{2} \mathrm{O}-\mathrm{H}_{2} \mathrm{O}$, $\mathrm{H}_{2} \mathrm{O}-\mathrm{H}_{2} \mathrm{~S}, \mathrm{H}_{2} \mathrm{O}-\mathrm{NH}_{3}$, and $\mathrm{H}_{2} \mathrm{O}-\mathrm{PH}_{3}$ using simple statistical mechanics. ${ }^{1,63}$ We use the rigid rotor and harmonic frequency approximations according to the standard text by McQuarrie. ${ }^{63}$ Harmonic frequencies and rotational constants for the complexes and their constituent monomers are obtained with the CCSD(T)-F12a/VTZ-F12 method.

All coupled cluster calculations assume a frozen core $(\mathrm{O}: 1 s ; \mathrm{N}: 1 s ; \mathrm{S}: 1 s, 2 s, 2 p ; \mathrm{P}: 1 s, 2 s, 2 p)$ and were performed using MOLPRO 2008.1. ${ }^{52}$ The optimization threshold criteria were set to gradient $=1 \times 10^{-6}$ a.u., step size $=1 \times 10^{-6}$ a.u., and energy $=1 \times 10^{-8}$ a.u. All single point energies were converged to $1 \times 10^{-9}$ a.u.

\section{RESULTS and DISCUSSION}

\section{A. Monomer}

In Table I we present the geometric parameters of $\mathrm{H}_{2} \mathrm{O}$, $\mathrm{H}_{2} \mathrm{~S}, \mathrm{NH}_{3}$, and $\mathrm{PH}_{3}$ optimized with the $\mathrm{CCSD}(\mathrm{T})$ method and the explicitly correlated CCSD(T)-F12 methods, as well as the experimentally determined values. As expected, the 
TABLE I. Optimized geometric parameters (in angstrom and degrees) of $\mathrm{H}_{2} \mathrm{O}, \mathrm{H}_{2} \mathrm{~S}, \mathrm{NH}_{3}$, and $\mathrm{PH}_{3}$.

\begin{tabular}{|c|c|c|c|c|c|c|c|c|c|c|c|c|}
\hline & \multicolumn{3}{|c|}{$\operatorname{CCSD}(\mathrm{T})-\mathrm{F} 12 \mathrm{a}$} & \multicolumn{3}{|c|}{$\operatorname{CCSD}(\mathrm{T})-\mathrm{F} 12 \mathrm{~b}$} & \multicolumn{5}{|c|}{$\operatorname{CCSD}(\mathrm{T})$} & \multirow[b]{2}{*}{ Expt. $^{\mathrm{a}}$} \\
\hline & VDZ-F12 & VTZ-F12 & VQZ-F12 & VDZ-F12 & VTZ-F12 & VQZ-F12 & AVDZ & AVTZ & AVQZ & AV5Z & AV6Z & \\
\hline \multicolumn{13}{|l|}{$\mathrm{H}_{2} \mathrm{O}$} \\
\hline$R_{\mathrm{OH}}$ & 0.9588 & 0.9587 & 0.9584 & 0.9585 & 0.9586 & 0.9583 & 0.9665 & 0.9616 & 0.9590 & 0.9584 & 0.9584 & 0.958 \\
\hline$\theta_{\mathrm{HOH}}$ & 104.36 & 104.40 & 104.46 & 104.34 & 104.40 & 104.45 & 103.94 & 104.18 & 104.37 & 104.43 & 104.45 & 104.5 \\
\hline \multicolumn{13}{|l|}{$\mathbf{H}_{2} \mathbf{S}$} \\
\hline$R_{\mathrm{SH}}$ & 1.3367 & 1.3382 & 1.3379 & 1.3366 & 1.3381 & 1.3378 & 1.3500 & 1.3391 & 1.3383 & 1.3379 & 1.3378 & 1.336 \\
\hline$\theta_{\mathrm{HSH}}$ & 92.19 & 92.28 & 92.36 & 92.19 & 92.28 & 92.36 & 92.37 & 92.25 & 92.35 & 92.36 & 92.36 & 92.1 \\
\hline \multicolumn{13}{|l|}{$\mathbf{N H}_{3}$} \\
\hline$R_{\mathrm{NH}}$ & 1.0123 & 1.0124 & 1.0121 & 1.0122 & 1.0124 & 1.0121 & 1.0237 & 1.0149 & 1.0128 & 1.0123 & 1.0122 & 1.012 \\
\hline$\theta_{\mathrm{HNH}}$ & 106.59 & 106.59 & 106.64 & 106.58 & 106.60 & 106.64 & 105.93 & 106.41 & 106.54 & 106.59 & 106.62 & 106.7 \\
\hline \multicolumn{13}{|l|}{$\mathbf{P H}_{3}$} \\
\hline$R_{\mathrm{PH}}$ & 1.4140 & 1.4149 & 1.4146 & 1.4140 & 1.4149 & 1.4145 & 1.4287 & 1.4167 & 1.4151 & 1.4147 & 1.4145 & 1.42 \\
\hline$\theta_{\mathrm{HPH}}$ & 93.48 & 93.54 & 93.57 & 93.48 & 93.53 & 93.56 & 93.42 & 93.46 & 93.56 & 93.57 & 93.56 & 93.3 \\
\hline
\end{tabular}

${ }^{\mathrm{a}}$ Equilibrium bond distances $\left(R_{e}\right)$ from Harmony et al. (Ref. 64).

CCSD(T) optimized geometric parameters converge uniformly as the cardinal number of the basis set increases. We find that bond lengths progressively shorten and bond angles steadily increase from AVDZ to AV6Z. Unfortunately, this same attractive convergence as the cardinal number of the basis set increases is not exhibited for the geometric parameters optimized using the explicitly correlated CCSD(T)-F12 methods. However, it is important to note that the variation between the VDZ-F12, VTZ-F12, and VQZ-F12 results with the explicitly correlated methods is considerably smaller than the $\operatorname{CCSD}(\mathrm{T})$ results with the equivalent Dunning basis sets.

For a given cardinal number, geometric parameters optimized using the explicitly correlated methods are in much better agreement with experiment than geometric parameters optimized with conventional $\operatorname{CCSD}(\mathrm{T})$. The $\operatorname{CCSD}(\mathrm{T})-\mathrm{F} 12$ optimized geometries obtained with the VTZ-F12 basis set are comparable to the $\mathrm{CCSD}(\mathrm{T}) / \mathrm{AV} 5 \mathrm{Z}$ results and in very close agreement with the experimental values. Impressively, geometric parameters optimized with the VDZ-F12 basis set are of similar accuracy to the $\operatorname{CCSD}(\mathrm{T}) / \mathrm{AVQZ}$ results and are at least an order of magnitude less computationally demanding.

There are small differences between geometric parameters optimized with the two different F12 approximations. We find that bond lengths obtained with the CCSD(T)-F12a method and a given basis set are consistently slightly longer than those obtained with the $\operatorname{CCSD}(\mathrm{T})-\mathrm{F} 12 \mathrm{~b}$ method. Similarly, we find that bond angles calculated with the $\operatorname{CCSD}(\mathrm{T})$ F12a method are consistently slightly larger than those calculated with the $\operatorname{CCSD}(\mathrm{T})-\mathrm{F} 12 \mathrm{~b}$ method. From the current limited data set, it appears that geometries optimized with the $\operatorname{CCSD}(\mathrm{T})-\mathrm{F} 12 \mathrm{~b}$ method are in slightly better agreement with the experimental results than geometries optimized with the $\operatorname{CCSD}(\mathrm{T})-\mathrm{F} 12 \mathrm{a}$ method.

In Table II we present the harmonic fundamental frequencies of $\mathrm{H}_{2} \mathrm{O}, \mathrm{H}_{2} \mathrm{~S}, \mathrm{NH}_{3}$, and $\mathrm{PH}_{3}$ calculated with the $\operatorname{CCSD}(\mathrm{T})$ method and the explicitly correlated CCSD(T)F12 methods. Similar to what was observed for the geomet- ric parameters, the $\mathrm{CCSD}(\mathrm{T})$ harmonic frequencies converge uniformly as the cardinal number of the basis set increases from AVDZ to AV5Z. Again somewhat troublesome, the explicitly correlated results do not appear to converge as the cardinal number of the basis set increases, although the oscillation is small.

In general, harmonic frequencies obtained using the explicitly correlated methods and even the smallest basis set are very close to the $\mathrm{CCSD}(\mathrm{T}) / \mathrm{AV} 5 \mathrm{Z}$ results, in agreement with the recent findings of Rauhut et al. ${ }^{65}$ If we exclude the VDZ-F12 results for $\mathrm{H}_{2} \mathrm{~S}$, we find that the explicitly correlated harmonic frequencies differ by only a few wave numbers as compared to the $\operatorname{CCSD}(\mathrm{T}) / \mathrm{AV} 5 \mathrm{Z}$ results. Interestingly, the $\mathrm{H}_{2} \mathrm{~S}$ harmonic frequencies obtained with the VDZF12 basis set are overestimated by $\sim 8 \mathrm{~cm}^{-1}$ compared to the $\mathrm{CCSD}(\mathrm{T}) / \mathrm{AV} 5 Z$ results. We suggest that perhaps the VDZF12 basis set for sulfur is not as well optimized as for the other atoms.

\section{B. Intermolecular distance}

The lowest energy structure of $\mathrm{H}_{2} \mathrm{O}-\mathrm{H}_{2} \mathrm{O}, \mathrm{H}_{2} \mathrm{O}-\mathrm{H}_{2} \mathrm{~S}$, $\mathrm{H}_{2} \mathrm{O}-\mathrm{NH}_{3}$, and $\mathrm{H}_{2} \mathrm{O}-\mathrm{PH}_{3}$ exhibits a near linear hydrogen bond with one of hydrogen atoms of the water subunit acting as the donor atom. Here we limit the discussion to just the intermolecular distances of the complexes, with the full optimized geometries given in Tables I-XII of the supplementary deposit. ${ }^{45}$ The intermolecular distance can be considered a guide to how well a particular ab initio method and basis set describes the intermolecular interactions between two monomers in a complex.

We have previously found the CP corrected $\operatorname{CCSD}(\mathrm{T}) /$ AVQZ optimized geometries of $\mathrm{H}_{2} \mathrm{O}-\mathrm{H}_{2} \mathrm{O}$ and $\mathrm{H}_{2} \mathrm{O}-\mathrm{NH}_{3}$ to be in good agreement with the respective experimental geometries determined by microwave spectroscopy. ${ }^{23,51,66,67}$ The largest variation between the calculated and experimental geometries occurs for the intermolecular geometric parameters. These parameters are generally accepted to be the 
TABLE II. Harmonic frequencies (in $\mathrm{cm}^{-1}$ ) of $\mathrm{H}_{2} \mathrm{O}, \mathrm{H}_{2} \mathrm{~S}, \mathrm{NH}_{3}$, and $\mathrm{PH}_{3}$.

\begin{tabular}{|c|c|c|c|c|c|c|c|c|c|c|}
\hline & \multicolumn{3}{|c|}{$\operatorname{CCSD}(\mathrm{T})-\mathrm{F} 12 \mathrm{a}$} & \multicolumn{3}{|c|}{$\operatorname{CCSD}(\mathrm{T})-\mathrm{F} 12 \mathrm{~b}$} & \multicolumn{4}{|c|}{$\operatorname{CCSD}(\mathrm{T})$} \\
\hline & VDZ-F12 & VTZ-F12 & VQZ-F12 & VDZ-F12 & VTZ-F12 & VQZ-F12 & AVDZ & AVTZ & AVQZ & AV5Z \\
\hline \multicolumn{11}{|c|}{$\mathrm{H}_{2} \mathrm{O}$} \\
\hline$v_{1}$ & 1651.1 & 1649.8 & 1649.0 & 1653.8 & 1651.2 & 1649.8 & 1638.2 & 1645.9 & 1650.1 & 1650.1 \\
\hline$v_{2}$ & 3833.8 & 3831.3 & 3834.1 & 3837.7 & 3833.4 & 3834.7 & 3786.5 & 3810.4 & 3830.6 & 3834.2 \\
\hline$v_{3}$ & 3942.6 & 3941.3 & 3944.9 & 3945.8 & 3943.1 & 3945.4 & 3904.5 & 3919.5 & 3940.3 & 3944.6 \\
\hline \multicolumn{11}{|c|}{$\mathbf{H}_{2} \mathbf{S}$} \\
\hline$v_{1}$ & 1217.6 & 1212.6 & 1211.5 & 1218.5 & 1213.6 & 1212.7 & 1197.9 & 1211.1 & 1211.6 & 1212.0 \\
\hline$v_{2}$ & 2731.3 & 2722.1 & 2724.1 & 2732.9 & 2722.8 & 2725.2 & 2704.9 & 2716.0 & 2722.2 & 2722.8 \\
\hline$v_{3}$ & 2746.9 & 2737.5 & 2738.7 & 2748.1 & 2738.0 & 2739.7 & 2725.6 & 2731.4 & 2738.0 & 2738.4 \\
\hline \multicolumn{11}{|c|}{$\mathbf{N H}_{3}$} \\
\hline$v_{1}$ & 1058.8 & 1056.1 & 1055.4 & 1061.1 & 1056.1 & 1055.9 & 1070.2 & 1062.8 & 1059.1 & 1057.7 \\
\hline$v_{2}$ & 1678.6 & 1674.4 & 1674.4 & 1680.3 & 1675.2 & 1675.2 & 1650.5 & 1672.4 & 1673.8 & 1674.7 \\
\hline$v_{3}$ & 3481.1 & 3477.3 & 3479.9 & 3482.7 & 3478.2 & 3480.3 & 3433.4 & 3463.9 & 3476.1 & 3479.0 \\
\hline$v_{4}$ & 3611.6 & 3609.3 & 3612.2 & 3612.5 & 3610.1 & 3612.4 & 3571.0 & 3592.7 & 3607.2 & 3610.5 \\
\hline \multicolumn{11}{|c|}{$\mathbf{P H}_{3}$} \\
\hline$v_{1}$ & 1010.9 & 1011.0 & 1010.9 & 1010.9 & 1011.3 & 1011.5 & 1010.5 & 1012.8 & 1012.3 & 1011.6 \\
\hline$v_{2}$ & 1142.7 & 1141.8 & 1142.4 & 1142.9 & 1142.2 & 1143.0 & 1138.4 & 1142.9 & 1143.0 & 1142.7 \\
\hline$v_{3}$ & 2424.9 & 2421.2 & 2422.4 & 2425.5 & 2420.9 & 2422.6 & 2395.0 & 2408.9 & 2421.0 & 2421.4 \\
\hline$v_{4}$ & 2431.7 & 2429.3 & 2439.5 & 2431.8 & 2428.9 & 2439.5 & 2406.8 & 2416.1 & 2428.5 & 2429.3 \\
\hline
\end{tabular}

most difficult to calculate and to accurately determine from experiment because of the relatively flat potential energy surface and anharmonic vibrational issues (vide infra). To our knowledge, the geometries of $\mathrm{H}_{2} \mathrm{O}-\mathrm{H}_{2} \mathrm{~S}$ and $\mathrm{H}_{2} \mathrm{O}-\mathrm{PH}_{3}$ have yet to be determined experimentally.

In Table III we present the $\operatorname{CCSD}(\mathrm{T})$ optimized intermolecular distances of $\mathrm{H}_{2} \mathrm{O}-\mathrm{H}_{2} \mathrm{O}, \mathrm{H}_{2} \mathrm{O}-\mathrm{H}_{2} \mathrm{~S}, \mathrm{H}_{2} \mathrm{O}-\mathrm{NH}_{3}$, and $\mathrm{H}_{2} \mathrm{O}-\mathrm{PH}_{3}$. If we first consider the standard $\operatorname{CCSD}(\mathrm{T}) / \mathrm{AVXZ}$ results, we find that the intermolecular distances of all four complexes become progressively shorter as the cardinal number of the basis set increases. This same trend is mirrored for the intermolecular distances obtained using the CP corrected optimization scheme. As expected, we find that the $\mathrm{CP}$ correction increases the intermolecular distance as compared to the distance obtained with the standard optimization scheme. The magnitude of the $\mathrm{CP}$ correction is greatest with the AVDZ basis set and becomes increasingly smaller for the AVTZ and AVQZ basis sets. We find that for a given cardinal number, the standard optimized $\operatorname{CCSD}(\mathrm{T})$ intermolecular distances are in slightly better agreement with the CBS limit than the CP corrected $\operatorname{CCSD}(\mathrm{T})$ intermolecular distances.

TABLE III. CCSD(T) intermolecular distances (in angstrom) for $\mathrm{H}_{2} \mathrm{O}-\mathrm{H}_{2} \mathrm{O}, \mathrm{H}_{2} \mathrm{O}-\mathrm{H}_{2} \mathrm{~S}, \mathrm{H}_{2} \mathrm{O}-\mathrm{NH}_{3}$, and $\mathrm{H}_{2} \mathrm{O}-\mathrm{PH}_{3}$. [The intermolecular distance is between the two heavy atoms, i.e., $R_{\mathrm{O} \cdots \mathrm{O}}, R_{\mathrm{O} \cdots \mathrm{S}}, R_{\mathrm{O}} \cdots \mathrm{N}$, and $R_{\mathrm{O} \cdots \mathrm{p} .}$.]

\begin{tabular}{|c|c|c|c|c|c|c|c|c|}
\hline & \multicolumn{2}{|c|}{$\mathrm{H}_{2} \mathrm{O}-\mathrm{H}_{2} \mathrm{O}$} & \multicolumn{2}{|c|}{$\mathrm{H}_{2} \mathrm{O}-\mathrm{H}_{2} \mathrm{~S}$} & \multicolumn{2}{|c|}{$\mathrm{H}_{2} \mathrm{O}-\mathrm{NH}_{3}$} & \multicolumn{2}{|c|}{$\mathrm{H}_{2} \mathrm{O}-\mathrm{PH}_{3}$} \\
\hline & Standard & $\mathrm{CP}$ & Standard & $\mathrm{CP}$ & Standard & $\mathrm{CP}$ & Standard & $\mathrm{CP}$ \\
\hline AVDZ & 2.9253 & 2.9875 & 3.5038 & 3.6034 & 2.9588 & 3.0106 & 3.6238 & 3.7322 \\
\hline AVTZ & 2.9137 & 2.9375 & 3.4801 & 3.5154 & 2.9388 & 2.9597 & 3.5999 & 3.6308 \\
\hline AVQZ & 2.9095 & 2.9212 & 3.4785 & 3.4936 & 2.9376 & 2.9479 & 3.5972 & 3.6101 \\
\hline $\mathrm{CBS}^{\mathrm{a}}$ & 2.9125 & & 3.4806 & & 2.9395 & & 3.5999 & \\
\hline $\mathrm{A}^{\prime} \mathrm{VDZ}$ & 2.9338 & 2.9892 & 3.5602 & 3.6221 & 2.9650 & 3.0126 & 3.7004 & 3.7707 \\
\hline $\mathrm{A}^{\prime} \mathrm{VTZ}$ & 2.9177 & 2.9419 & 3.4898 & 3.5234 & 2.9419 & 2.9627 & 3.6085 & 3.6371 \\
\hline $\mathrm{A}^{\prime} \mathrm{VQZ}$ & 2.9123 & 2.9221 & 3.4867 & 3.4983 & 2.9392 & 2.9475 & 3.6031 & 3.6137 \\
\hline $\mathrm{CBS}^{\mathrm{b}}$ & 2.9126 & & 3.4773 & & 2.9396 & & 3.5976 & \\
\hline VDZ & 2.9245 & 3.0638 & 3.6318 & 3.7635 & 2.9479 & 3.1107 & 3.7508 & 3.9267 \\
\hline VTZ & 2.9163 & 2.9815 & 3.5272 & 3.5845 & 2.9584 & 3.0139 & 3.5916 & 3.7067 \\
\hline VQZ & 2.9101 & 2.9397 & 3.5095 & 3.5260 & 2.9465 & 2.9701 & 3.6191 & 3.6433 \\
\hline $\mathrm{CBS}^{\mathrm{c}}$ & 2.9169 & & 3.4880 & & 2.9460 & & 3.6126 & \\
\hline
\end{tabular}

${ }^{\mathrm{a}}$ Extrapolation to the CBS limit utilizes the AVQZ and AV5Z results.

${ }^{b}$ Extrapolation to the CBS limit utilizes the $\mathrm{A}^{\prime} \mathrm{VQZ}$ and $\mathrm{A}^{\prime} \mathrm{V} 5 \mathrm{Z}$ results.

${ }^{c}$ Extrapolation to the CBS limit utilizes the VQZ and V5Z results. 
TABLE IV. CCSD(T)-F12 intermolecular distances (in angstrom) for $\mathrm{H}_{2} \mathrm{O}-\mathrm{H}_{2} \mathrm{O}, \mathrm{H}_{2} \mathrm{O}-\mathrm{H}_{2} \mathrm{~S}, \mathrm{H}_{2} \mathrm{O}-\mathrm{NH}_{3}$, and $\mathrm{H}_{2} \mathrm{O}-\mathrm{PH}_{3}$. [The intermolecular distance is between the two heavy atoms, i.e., $R_{\mathrm{O} \cdots \mathrm{O}}, R_{\mathrm{O} \cdots \mathrm{S}}, R_{\mathrm{O}} \cdots \mathrm{N}$, and $R_{\mathrm{O} \cdots \mathrm{p} \text {. }] ~}$

\begin{tabular}{|c|c|c|c|c|c|c|c|c|}
\hline & \multicolumn{2}{|c|}{$\mathrm{H}_{2} \mathrm{O}-\mathrm{H}_{2} \mathrm{O}$} & \multicolumn{2}{|c|}{$\mathrm{H}_{2} \mathrm{O}-\mathrm{H}_{2} \mathrm{~S}$} & \multicolumn{2}{|c|}{$\mathrm{H}_{2} \mathrm{O}-\mathrm{NH}_{3}$} & \multicolumn{2}{|c|}{$\mathrm{H}_{2} \mathrm{O}-\mathrm{PH}_{3}$} \\
\hline & F12a & $\mathrm{F} 12 \mathrm{~b}$ & F12a & $\mathrm{F} 12 \mathrm{~b}$ & F12a & $\mathrm{F} 12 \mathrm{~b}$ & F12a & $\mathrm{F} 12 \mathrm{~b}$ \\
\hline VDZ-F12 & 2.9145 & 2.9171 & 3.4636 & 3.4694 & 2.9414 & 2.9446 & 3.5853 & 3.5917 \\
\hline VTZ-F12 & 2.9132 & 2.9131 & 3.4789 & 3.4792 & 2.9393 & 2.9397 & 3.6009 & 3.6013 \\
\hline VQZ-F12 & 2.9131 & 2.9128 & 3.4807 & 3.4792 & 2.9395 & 2.9395 & 3.6007 & 3.6004 \\
\hline
\end{tabular}

The partially augmented $\operatorname{CCSD}(\mathrm{T}) / \mathrm{A}^{\prime} \mathrm{V} X \mathrm{Z}$ results display similar trends to the fully augmented basis sets with the standard and $\mathrm{CP}$ corrected intermolecular distances decreasing as the cardinal number of the basis set increases. Interestingly, we find that the difference between the standard and $\mathrm{CP}$ corrected intermolecular distances is smaller for the $\operatorname{CCSD}(\mathrm{T}) / \mathrm{A}^{\prime} \mathrm{VXZ}$ results than for the $\mathrm{CCSD}(\mathrm{T}) / \mathrm{AVXZ}$ results. This suggests that the effects of BSSE are reduced when only the heavy atoms are augmented with diffuse basis functions. For completeness, if we now consider the $\operatorname{CCSD}(\mathrm{T}) / \mathrm{VXZ}$ results, i.e., with no diffuse basis functions, we find that the difference between the standard and $\mathrm{CP}$ corrected $\operatorname{CCSD}(\mathrm{T})$ intermolecular distances is greater than for either the $\mathrm{AVXZ}$ or $\mathrm{A}^{\prime} \mathrm{V} X \mathrm{Z}$ results.

Encouragingly, we find that extrapolation of either the $\operatorname{CCSD}(\mathrm{T}) / \mathrm{AVXZ}$ or the $\operatorname{CCSD}(\mathrm{T}) / \mathrm{A}^{\prime} \mathrm{V} X \mathrm{Z}$ results yields CBS intermolecular distances that are very similar. For the first row complexes, these CBS extrapolated intermolecular distances are essentially identical $(\sim 0.0001 \AA)$, whereas the second row complexes differ by $\sim 0.003 \AA$. We suggest that the diffuse basis functions on the hydrogen atoms of the $\mathrm{AVXZ}$ basis sets are supplementing the basis set requirements of the second row elements and that perhaps additional basis functions on the heavy atoms are necessary. Extrapolation of the nonaugmented $\operatorname{CCSD}(\mathrm{T}) / \mathrm{VXZ}$ results gives CBS limit intermolecular distances that are slightly longer by $\sim 0.004-0.015 \AA$, as compared to the fully and partially augmented CCSD(T)/CBS limits. For $\mathrm{H}_{2} \mathrm{O}-\mathrm{H}_{2} \mathrm{O}$, our CCSD(T)/AVXZ CBS intermolecular distance is in good agreement with the value of $2.909 \AA$ by Min et al. obtained using a slightly different CBS extrapolation scheme that was directly applied to the $\operatorname{CCSD}(\mathrm{T}) / \mathrm{AVTZ}$ and $\operatorname{CCSD}(\mathrm{T}) / \mathrm{AVQZ}$ optimized intermolecular distances rather than constructing an intermolecular potential. ${ }^{16}$

It may seem somewhat surprising that our $\operatorname{CCSD}(\mathrm{T}) /$ CBS intermolecular distances are slightly longer than the quadruple- $\zeta$ results when there has been a progressive contraction of the intermolecular distance from double- $\zeta$ to quadruple- $\zeta$. However, the $\mathrm{AVXZ}$ and $\mathrm{A}^{\prime} \mathrm{VXZ} \operatorname{CCSD}(\mathrm{T}) /$ CBS intermolecular distances are in excellent agreement with the explicitly correlated $\mathrm{CCSD}(\mathrm{T})-\mathrm{F} 12$ results (vide infra). Furthermore we find that for $\mathrm{H}_{2} \mathrm{O}-\mathrm{H}_{2} \mathrm{O}$, the $\operatorname{CCSD}(\mathrm{T}) / \mathrm{A}^{\prime} \mathrm{V} 5 \mathrm{Z}$ optimized intermolecular distance is $2.9127 \AA$, which is slightly longer than the $\operatorname{CCSD}(\mathrm{T}) / \mathrm{A}^{\prime} \mathrm{VQZ}$ value and is in close agreement with the CBS distance. We suggest that this nonasymtopic convergence of the intermolecular distance represents competition between basis set incompleteness error and BSSE in our calculations.
It is important to note that the calculated intermolecular distances presented in Tables III and IV are equilibrium bond lengths $\left(R_{e}\right)$ and represent the minimum of the potential energy surface. These calculated values are not directly comparable with the experimentally determined intermolecular distances of $\mathrm{H}_{2} \mathrm{O}-\mathrm{H}_{2} \mathrm{O}$ and $\mathrm{H}_{2} \mathrm{O}-\mathrm{NH}_{3}$, which are measured in the vibrational ground state $\left(R_{0}\right)$ and do not allow the monomer geometries to relax. ${ }^{66,67}$ The intermolecular potentials of $\mathrm{H}_{2} \mathrm{O}-\mathrm{H}_{2} \mathrm{O}$ and $\mathrm{H}_{2} \mathrm{O}-\mathrm{NH}_{3}$ are highly anharmonic and as such the value of $R_{0}$ is expected to be significantly longer than the value of $R_{e}$. To facilitate a more fair comparison between the calculated $\left(R_{e}\right)$ and experimental $\left(R_{0}\right)$ intermolecular distances we have calculated a ground state anharmonic vibrational correction to our calculated equilibrium distances. We calculate the expectation value of the one-dimensional $R_{\mathrm{O} \cdots \mathrm{O}}, R_{\mathrm{O} \cdots \mathrm{S}}, R_{\mathrm{O} \cdots \mathrm{N}}$, and $R_{\mathrm{O} \cdots \mathrm{P}}$ intermolecular stretching potentials in the vibrational ground state. This procedure is described in more detail in Sec. II. We find that the anharmonic correction to the intermolecular distance is inversely proportional to the interaction energy (vide infra) and is $+0.031 \AA$ for $\mathrm{H}_{2} \mathrm{O}-\mathrm{NH}_{3},+0.035 \AA$ for $\mathrm{H}_{2} \mathrm{O}-\mathrm{H}_{2} \mathrm{O}$, $+0.037 \AA$ for $\mathrm{H}_{2} \mathrm{O}-\mathrm{H}_{2} \mathrm{~S}$, and $+0.038 \AA$ for $\mathrm{H}_{2} \mathrm{O}-\mathrm{PH}_{3}$.

The anharmonic vibrational correction that we estimate for $\mathrm{H}_{2} \mathrm{O}-\mathrm{H}_{2} \mathrm{O}$ is similar to the $+0.029 \AA$ estimated by Odutola and Dyke in the original experimental investigation using a one-dimensional normal mode approach with low level $a b$ initio parameters. ${ }^{67}$ If we add our one-dimensional anharmonic vibrational correction to the CCSD(T)/CBS limit $R_{e}$ value we get a calculated value for $R_{0}$ of $2.947 \AA$. This value is very similar to the often quoted estimated "experimental" equilibrium distance for water dimer of $2.946 \AA \AA^{67}{ }^{67}$ However, this simple procedure to estimate the anharmonic vibrational correction to the intermolecular distance can clearly be improved by considering the effects of other vibrational modes. We have calculated the difference between $R_{e}$ and $R_{0}$ to be $0.06 \AA$ using vibrational second-order perturbation theory (VPT2) as implemented in ACES II with the CCSD(T)/AVTZ method. ${ }^{15,68}$ The magnitude of this correction is very similar to the $0.06 \AA$ difference between $R_{0}$ and $R_{e}$ previously determined by Leforestier et al. ${ }^{69}$ using the CC-pol-8s potential energy surface. ${ }^{70}$ If we add our VPT2 anharmonic vibrational correction of $0.06 \AA$ to the CCSD(T)/CBS limit of $R_{e}$ we get $R_{0}=2.972 \AA$, which is in excellent agreement with the experimental value of $2.976 \AA \AA^{67}$

For $\mathrm{H}_{2} \mathrm{O}-\mathrm{NH}_{3}$, our estimate of $R_{0}$ using the onedimensional anharmonic vibrational correction is $2.9703 \AA$, which is $\sim 0.02 \AA$ shorter than the experimentally determined $R_{0}$ of $2.989 \AA{ }^{66}$ We anticipate that a VPT2 anharmonic vibrational correction for $\mathrm{H}_{2} \mathrm{O}-\mathrm{NH}_{3}$ would increase 
TABLE V. CCSD(T) interaction energies (in kcal mol ${ }^{-1}$ ) for $\mathrm{H}_{2} \mathrm{O}-\mathrm{H}_{2} \mathrm{O}, \mathrm{H}_{2} \mathrm{O}-\mathrm{H}_{2} \mathrm{~S}, \mathrm{H}_{2} \mathrm{O}-\mathrm{NH}_{3}$, and $\mathrm{H}_{2} \mathrm{O}-\mathrm{PH}_{3}$. [All calculations are carried out at the $\operatorname{CCSD}(\mathrm{T})-\mathrm{F} 12 \mathrm{a} / \mathrm{VQZ}-\mathrm{F} 12$ optimized geometry.]

\begin{tabular}{|c|c|c|c|c|c|c|c|c|}
\hline & \multicolumn{2}{|c|}{$\mathrm{H}_{2} \mathrm{O}-\mathrm{H}_{2} \mathrm{O}$} & \multicolumn{2}{|c|}{$\mathrm{H}_{2} \mathrm{O}-\mathrm{H}_{2} \mathrm{~S}$} & \multicolumn{2}{|c|}{$\mathrm{H}_{2} \mathrm{O}-\mathrm{NH}_{3}$} & \multicolumn{2}{|c|}{$\mathrm{H}_{2} \mathrm{O}-\mathrm{PH}_{3}$} \\
\hline & Standard & $\mathrm{CP}$ & Standard & $\mathrm{CP}$ & Standard & $\mathrm{CP}$ & Standard & $\mathrm{CP}$ \\
\hline AVDZ & -5.30 & -4.39 & -3.34 & -2.41 & -6.84 & -5.66 & -2.69 & -1.91 \\
\hline AVTZ & -5.22 & -4.75 & -3.18 & -2.76 & -6.62 & -6.18 & -2.67 & -2.35 \\
\hline AVQZ & -5.10 & -4.91 & -3.00 & -2.85 & -6.51 & -6.33 & -2.55 & -2.46 \\
\hline AV5Z & -5.03 & -4.94 & -2.95 & -2.88 & -6.45 & -6.37 & -2.52 & -2.48 \\
\hline $\mathrm{CBS}^{\mathrm{a}}$ & -4.99 & & -2.91 & & -6.40 & & -2.49 & \\
\hline $\mathrm{A}^{\prime} \mathrm{VDZ}$ & -5.15 & -4.39 & -2.85 & -2.36 & -6.47 & -5.55 & -2.20 & -1.78 \\
\hline $\mathrm{A}^{\prime} \mathrm{VTZ}$ & -5.05 & -4.69 & -2.92 & -2.65 & -6.46 & -6.07 & -2.49 & -2.26 \\
\hline $\mathrm{A}^{\prime} \mathrm{VQZ}$ & -5.01 & -4.87 & -2.91 & -2.81 & -6.43 & -6.28 & -2.50 & -2.42 \\
\hline$A^{\prime} V 5 Z$ & -4.99 & -4.93 & -2.91 & -2.87 & -6.41 & -6.35 & -2.49 & -2.47 \\
\hline $\mathrm{CBS}^{\mathrm{b}}$ & -4.98 & & -2.91 & & -6.40 & & -2.50 & \\
\hline VDZ & -7.00 & -3.75 & -2.67 & -1.59 & -7.67 & -4.72 & -1.90 & -1.17 \\
\hline VTZ & -5.88 & -4.34 & -2.77 & -2.23 & -7.03 & -5.50 & -2.31 & -1.87 \\
\hline VQZ & -5.40 & -4.69 & -2.85 & -2.60 & -6.68 & -5.98 & -2.48 & -2.22 \\
\hline V5Z & -5.12 & -4.87 & -2.91 & -2.80 & -6.46 & -6.25 & -2.49 & -2.39 \\
\hline $\mathrm{CBS}^{\mathrm{c}}$ & -5.07 & & -3.01 & & -6.46 & & -2.55 & \\
\hline
\end{tabular}

${ }^{\mathrm{a}}$ Extrapolation to the CBS limit utilizes the AVQZ and AV5Z results.

${ }^{\mathrm{b}}$ Extrapolation to the CBS limit utilizes the $\mathrm{A}^{\prime} \mathrm{VQZ}$ and $\mathrm{A}^{\prime} \mathrm{V} 5 \mathrm{Z}$ results.

${ }^{c}$ Extrapolation to the CBS limit utilizes the VQZ and V5Z results.

the intermolecular $R_{0}$ distance further. Unfortunately, we were unable to use VPT2 to determine the anharmonic vibrational correction to the intermolecular distances of $\mathrm{H}_{2} \mathrm{O}-\mathrm{NH}_{3}$ or the other complexes as there are numerical stability problems when calculating cubic and quartic force constants of low frequency vibrational modes (harmonic frequency of $<100 \mathrm{~cm}^{-1}$ ).

In Table IV we present the $\operatorname{CCSD}(\mathrm{T})-\mathrm{F} 12$ optimized intermolecular distances of $\mathrm{H}_{2} \mathrm{O}-\mathrm{H}_{2} \mathrm{O}, \mathrm{H}_{2} \mathrm{O}-\mathrm{H}_{2} \mathrm{~S}, \mathrm{H}_{2} \mathrm{O}-\mathrm{NH}_{3}$, and $\mathrm{H}_{2} \mathrm{O}-\mathrm{PH}_{3}$. In general, the intermolecular distances obtained with the explicitly correlated methods are in very good agreement with the $\operatorname{CCSD}(\mathrm{T}) / \mathrm{CBS}$ limits in Table III. For a given cardinal number, we find that the $\operatorname{CCSD}(\mathrm{T})-\mathrm{F} 12 / \mathrm{VXZ}-\mathrm{F} 12$ intermolecular distances are in much better agreement with the CBS limit than the conventional $\operatorname{CCSD}(\mathrm{T})$ intermolecular distances obtained with or without $\mathrm{CP}$ correction. However, as was previously observed for monomer geometries (Table I), there is no clear convergence of the intermolecular distances as we increase the cardinal number of the VXZ-F12 basis sets.

The intermolecular distances for $\mathrm{H}_{2} \mathrm{O}-\mathrm{H}_{2} \mathrm{O}$ and $\mathrm{H}_{2} \mathrm{O}-\mathrm{NH}_{3}$ obtained with the CCSD(T)-F12 methods appear to be in slightly better agreement with the CBS limit than the intermolecular distances for $\mathrm{H}_{2} \mathrm{O}-\mathrm{H}_{2} \mathrm{~S}$ and $\mathrm{H}_{2} \mathrm{O}-\mathrm{PH}_{3}$. We suggest that these differences are perhaps due to the additional basis set requirements of second row elements. We find that the two $\operatorname{CCSD}(\mathrm{T})-\mathrm{F} 12$ methods perform equally well when describing the intermolecular interactions in $\mathrm{H}_{2} \mathrm{O}-\mathrm{H}_{2} \mathrm{O}, \mathrm{H}_{2} \mathrm{O}-\mathrm{H}_{2} \mathrm{~S}, \mathrm{H}_{2} \mathrm{O}-\mathrm{NH}_{3}$, and $\mathrm{H}_{2} \mathrm{O}-\mathrm{PH}_{3}$.

In summary, we recommend optimizing small molecular complexes with either the CCSD(T)-F12a or CCSD(T)-F12b methods and the largest practicable VXZ-F12 basis set. When these explicitly correlated methods are not possible we suggest optimizing with the $\operatorname{CCSD}(\mathrm{T})$ method and the largest practicable $\mathrm{A}^{\prime} \mathrm{V} X \mathrm{Z}$ basis set. We believe that selectively augmenting only the heavy atoms in a molecule with diffuse basis functions is preferable to the use of a CP corrected optimization scheme. The results of the former approach are likely in closer agreement with the CBS limit and at lower computational cost.

\section{Interaction energies}

In Table $\mathrm{V}$ we present the standard and $\mathrm{CP}$ corrected $\mathrm{CCSD}(\mathrm{T})$ interaction energies for $\mathrm{H}_{2} \mathrm{O}-\mathrm{H}_{2} \mathrm{O}, \mathrm{H}_{2} \mathrm{O}-\mathrm{H}_{2} \mathrm{~S}$, $\mathrm{H}_{2} \mathrm{O}-\mathrm{NH}_{3}$, and $\mathrm{H}_{2} \mathrm{O}-\mathrm{PH}_{3}$. If we first consider the $\mathrm{CCSD}(\mathrm{T}) / \mathrm{AVXZ}$ results, we find that both the standard and $\mathrm{CP}$ corrected interaction energies systematically converge to the CBS limit but from opposite directions. As expected, the $\mathrm{CP}$ corrected interaction energies are smaller than the equivalent standard CCSD $(\mathrm{T})$ interaction energies obtained with the same basis set. In general, we find that the standard $\operatorname{CCSD}(\mathrm{T})$ interaction energies obtained with the AVDZ and AVTZ basis sets are in better agreement with the $\operatorname{CCSD}(\mathrm{T}) /$ CBS limit than the CP corrected CCSD(T) interaction energies. For the larger AVQZ and AV5Z basis sets, where BSSE is smaller, standard and CP corrected interaction energies are similar and it is not consistent which of the two approaches is closest to the $\operatorname{CCSD}(\mathrm{T}) / \mathrm{CBS}$ limit.

We find that extrapolation of either the CCSD(T)/ AVXZ or the $\operatorname{CCSD}(\mathrm{T}) / \mathrm{A}^{\prime} \mathrm{VXZ}$ results yields CBS interaction energies that are essentially identical (within $0.01 \mathrm{kcal} \mathrm{mol}^{-1}$ ). This indicates that both the fully and selectively augmented basis sets are describing the dimers reasonably well. In contrast we find that extrapolation of $\operatorname{CCSD}(\mathrm{T}) / \mathrm{VXZ}$ results yields CBS limit interaction energies that are slightly larger $\left(\sim 0.05-0.10 \mathrm{kcal} \mathrm{mol}^{-1}\right)$ than the CBS limit obtained with the $\operatorname{CCSD}(\mathrm{T}) / \mathrm{AVXZ}$ or $\mathrm{CCSD}(\mathrm{T}) / \mathrm{A}^{\prime} \mathrm{V} X \mathrm{Z}$ results. 
TABLE VI. CCSD(T)-F12 interaction energies (in kcal mol ${ }^{-1}$ ) for $\mathrm{H}_{2} \mathrm{O}-\mathrm{H}_{2} \mathrm{O}, \mathrm{H}_{2} \mathrm{O}-\mathrm{H}_{2} \mathrm{~S}, \mathrm{H}_{2} \mathrm{O}-\mathrm{NH}_{3}$, and $\mathrm{H}_{2} \mathrm{O}-\mathrm{PH}_{3}$. [All calculations are carried out at the $\operatorname{CCSD}(\mathrm{T})-\mathrm{F} 12 \mathrm{a} / \mathrm{VQZ}-\mathrm{F} 12$ optimized geometry.]

\begin{tabular}{|c|c|c|c|c|c|c|c|c|}
\hline & \multicolumn{2}{|c|}{$\mathrm{H}_{2} \mathrm{O}-\mathrm{H}_{2} \mathrm{O}$} & \multicolumn{2}{|c|}{$\mathrm{H}_{2} \mathrm{O}-\mathrm{H}_{2} \mathrm{~S}$} & \multicolumn{2}{|c|}{$\mathrm{H}_{2} \mathrm{O}-\mathrm{NH}_{3}$} & \multicolumn{2}{|c|}{$\mathrm{H}_{2} \mathrm{O}-\mathrm{PH}_{3}$} \\
\hline & $\mathrm{F} 12 \mathrm{a}$ & $\mathrm{F} 12 \mathrm{~b}$ & $\mathrm{~F} 12 \mathrm{a}$ & $\mathrm{F} 12 \mathrm{~b}$ & $\mathrm{~F} 12 \mathrm{a}$ & $\mathrm{F} 12 \mathrm{~b}$ & F12a & $\mathrm{F} 12 \mathrm{~b}$ \\
\hline VDZ-F12 & -5.08 & -5.04 & -3.02 & -2.98 & -6.50 & -6.44 & -2.59 & -2.55 \\
\hline VTZ-F12 & -5.02 & -5.02 & -2.95 & -2.94 & -6.44 & -6.44 & -2.51 & -2.51 \\
\hline VQZ-F12 & -4.99 & -5.00 & -2.93 & -2.94 & -6.41 & -6.42 & -2.51 & -2.51 \\
\hline $\mathrm{CBS}^{\mathrm{a}}$ & -4.98 & & -2.91 & & -6.40 & & -2.50 & \\
\hline
\end{tabular}

${ }^{\mathrm{a}}$ Extrapolation to the CBS limit utilizes conventional CCSD(T) $\mathrm{A}^{\prime} \mathrm{VQZ}$ and $\mathrm{A}^{\prime} \mathrm{V} 5 \mathrm{Z}$ results.

Interaction energies obtained with the partially augmented $\mathrm{A}^{\prime} \mathrm{VXZ}$ basis sets appear smaller than the corresponding $\mathrm{AVXZ}$ interaction energies and are closer to the CBS limit. In general, we find that restricting diffuse basis functions to the heavy atoms only results in standard interaction energies that are more accurate than the interaction energies obtained with a fully augmented basis set of the next cardinal number, i.e., $\mathrm{A}^{\prime} \mathrm{VDZ}$ is better than AVTZ, $\mathrm{A}^{\prime} \mathrm{VTZ}$ is better than AVQZ, etc. We also find that the difference between the standard and $\mathrm{CP}$ corrected $\operatorname{CCSD}(\mathrm{T})$ interaction energies with the $\mathrm{A}^{\prime} \mathrm{VXZ}$ basis sets is smaller than the difference between the full AVXZ basis sets. This behavior indicates that including diffuse basis functions on the hydrogen atoms contributes significantly to BSSE in these weakly bound complexes. ${ }^{30}$ Interestingly for all four complexes, we find that the standard $\operatorname{CCSD}(\mathrm{T})$ interaction energies obtained with the $\mathrm{A}^{\prime} \mathrm{V} X \mathrm{Z}$ basis sets are in better agreement with the $\operatorname{CCSD}(\mathrm{T}) / \mathrm{CBS}$ limit than the corresponding $\mathrm{CP}$ corrected $\mathrm{CCSD}(\mathrm{T})$ interaction energies.

We observe a slightly different convergence behavior for the $\operatorname{CCSD}(\mathrm{T})$ interaction energies obtained without any diffuse basis functions (the $\mathrm{VXZ}$ basis sets) as compared to the $\mathrm{AVXZ}$ and $\mathrm{A}^{\prime} \mathrm{V} X \mathrm{Z}$ results. For the first row complexes, $\mathrm{H}_{2} \mathrm{O}-\mathrm{H}_{2} \mathrm{O}$ and $\mathrm{H}_{2} \mathrm{O}-\mathrm{NH}_{3}$, the standard and $\mathrm{CP}$ corrected interaction energies again systematically converge to the CBS limit but from opposite directions. However, even with the V5Z basis set, the difference between the standard and $\mathrm{CP}$ corrected results is much larger than with the AV5Z or $\mathrm{A}^{\prime} \mathrm{V} 5 \mathrm{Z}$ basis sets. For the second row complexes, $\mathrm{H}_{2} \mathrm{O}-\mathrm{H}_{2} \mathrm{~S}$ and $\mathrm{H}_{2} \mathrm{O}-\mathrm{PH}_{3}$, we see that both the standard and CP corrected interaction energies approach the $\mathrm{CCSD}(\mathrm{T}) / \mathrm{VXZ}$ CBS limit from the same direction, becoming progressively larger as the cardinal number of the basis set increases. This behavior can be rationalized if we consider that the more spatially diffuse electrons of the second row elements are likely to require more diffuse basis functions for an accurate description.

In Table VI we present the CCSD(T)-F12 calculated interaction energies for $\mathrm{H}_{2} \mathrm{O}-\mathrm{H}_{2} \mathrm{O}, \mathrm{H}_{2} \mathrm{O}-\mathrm{H}_{2} \mathrm{~S}, \mathrm{H}_{2} \mathrm{O}-\mathrm{NH}_{3}$, and $\mathrm{H}_{2} \mathrm{O}-\mathrm{PH}_{3}$. Unlike the $\mathrm{CCSD}(\mathrm{T})-\mathrm{F} 12$ geometric parameters and harmonic frequencies in Tables I, II, and IV, the CCSD(T)-F12 interaction energies systematically converge to the CBS limit as the cardinal number increases. We find that $\operatorname{CCSD}(\mathrm{T})-\mathrm{F} 12$ calculated interaction energies obtained with the VTZ-F12 basis set are in better agreement with the $\operatorname{CCSD}(\mathrm{T}) / \mathrm{CBS}$ limit (Table V) than the conventional
CCSD(T)/AV5Z results. Interaction energies calculated with the VDZ-F12 basis set are of equal accuracy to the CCSD(T)/AVQZ results and are significantly cheaper.

In summary, we recommend the use of the explicitly correlated $\operatorname{CCSD}(\mathrm{T})-\mathrm{F} 12$ methods for determining the interaction energy of a complex. These newly developed methods perform very well, giving results that are close to the $\mathrm{CCSD}(\mathrm{T}) / \mathrm{CBS}$ limit results. When these explicitly correlated methods are not possible we suggest calculating the interaction energy using the $\operatorname{CCSD}(\mathrm{T})$ method and the largest practicable $\mathrm{A}^{\prime} \mathrm{V} X \mathrm{Z}$ basis set. We find that interaction energies obtained with even modest $\mathrm{A}^{\prime} \mathrm{V} X \mathrm{Z}$ basis sets are in very good agreement with the $\operatorname{CCSD}(\mathrm{T}) / \mathrm{CBS}$ limit and are generally more accurate than $\mathrm{CP}$ corrected $\mathrm{CCSD}(\mathrm{T})$ interaction energies obtained with the equivalent AVXZ basis set.

\section{Atmospheric implications}

In Table VII we compare thermodynamic parameters and the equilibrium constant of formation for $\mathrm{H}_{2} \mathrm{O}-\mathrm{H}_{2} \mathrm{O}$, $\mathrm{H}_{2} \mathrm{O}-\mathrm{H}_{2} \mathrm{~S}, \mathrm{H}_{2} \mathrm{O}-\mathrm{NH}_{3}$, and $\mathrm{H}_{2} \mathrm{O}-\mathrm{PH}_{3}$. We have calculated these values with a simple statistical mechanics approach, 1,63 which should be adequate to explain the relative trends between the complexes. More sophisticated approaches are available to determine the thermodynamic parameters of weakly bound complexes but these are highly individualized and often include experimental data. ${ }^{71-73}$ For example, the equilibrium constant of formation for $\mathrm{H}_{2} \mathrm{O}-\mathrm{H}_{2} \mathrm{O}$ has been previously calculated to be $\sim 0.05$ using an $a b$ initio potential energy surface that is fitted to experimental vibrationalrotation-tunneling transitions. ${ }^{73}$ This previously calculated

TABLE VII. Thermodynamic parameters (in $\mathrm{kcal} \mathrm{mol}^{-1}$ ) and the equilibrium constant of formation for $\mathrm{H}_{2} \mathrm{O}-\mathrm{H}_{2} \mathrm{O}, \mathrm{H}_{2} \mathrm{O}-\mathrm{H}_{2} \mathrm{~S}, \mathrm{H}_{2} \mathrm{O}-\mathrm{NH}_{3}$, and $\mathrm{H}_{2} \mathrm{O}-\mathrm{PH}_{3}$. [All calculations are carried out at the CCSD(T)-F12a/VQZ-F12 optimized geometry.].

\begin{tabular}{lcccc}
\hline \hline & $\mathrm{H}_{2} \mathrm{O}-\mathrm{H}_{2} \mathrm{O}$ & $\mathrm{H}_{2} \mathrm{O}-\mathrm{H}_{2} \mathrm{~S}$ & $\mathrm{H}_{2} \mathrm{O}-\mathrm{NH}_{3}$ & $\mathrm{H}_{2} \mathrm{O}-\mathrm{PH}_{3}$ \\
\hline Interaction energy $^{\mathrm{a}}$ & -4.99 & -2.93 & -6.41 & -2.51 \\
$\mathrm{ZPVE}^{\mathrm{b}}$ & +2.08 & +1.41 & +2.19 & +1.26 \\
$\Delta_{f} H(298 \mathrm{~K})$ & -3.34 & -1.55 & -4.65 & -1.11 \\
$T \Delta_{f} S(298 \mathrm{~K})$ & -5.95 & -4.91 & -4.80 & -4.00 \\
$\Delta_{f} G(298 \mathrm{~K})$ & +2.61 & +3.37 & +0.15 & +2.89 \\
$k_{\mathrm{eq}}(298 \mathrm{~K})$ & & & & \\
\hline \hline
\end{tabular}

${ }^{\mathrm{a} C C S D(T)-F 12 a / V Q Z-F 12 . ~}$

${ }^{\mathrm{b}}$ Obtained with CCSD(T)-F12a/VTZ-F12 harmonic frequencies. 
equilibrium constant is $\sim 5$ times larger than our present value (vide infra).

We have used CCSD(T)-F12a/VTZ-F12 harmonic frequencies to determine the zero point vibrational energy correction and $\operatorname{CCSD}(\mathrm{T})-\mathrm{F} 12 \mathrm{a} / \mathrm{VTZ}-\mathrm{F} 12$ harmonic frequencies and rotational constants for the thermodynamic parameters. For the monomer subunits, this level of theory produced frequencies in excellent agreement with the CCSD(T)/AV5Z results (Table II). The complete $\operatorname{CCSD}(\mathrm{T})-\mathrm{F} 12 \mathrm{a}$ and $\operatorname{CCSD}(\mathrm{T})-\mathrm{F} 12 \mathrm{~b}$ harmonic frequencies obtained with the VDZ-F12 and VTZ-F12 basis sets are included in Tables XIII and XIV of the supplementary deposit. ${ }^{45}$

We find that $\mathrm{H}_{2} \mathrm{O}-\mathrm{NH}_{3}$ exhibits the largest interaction energy followed by $\mathrm{H}_{2} \mathrm{O}-\mathrm{H}_{2} \mathrm{O}, \mathrm{H}_{2} \mathrm{O}-\mathrm{H}_{2} \mathrm{~S}$, and $\mathrm{H}_{2} \mathrm{O}-\mathrm{PH}_{3}$. Furthermore, we find that first row complexes are more strongly bound than the equivalent second row complexes, i.e., the interaction energy of $\mathrm{H}_{2} \mathrm{O}-\mathrm{H}_{2} \mathrm{O}$ is greater than $\mathrm{H}_{2} \mathrm{O}-\mathrm{H}_{2} \mathrm{~S}$. Our present best estimates of the interaction energy of $\mathrm{H}_{2} \mathrm{O}-\mathrm{H}_{2} \mathrm{O}$ and $\mathrm{H}_{2} \mathrm{O}-\mathrm{NH}_{3}$ are slightly lower than the values we previously determined using a CBS extrapolation using CCSD(T)/AVTZ and CCSD(T)/AVQZ results. ${ }^{23,51}$ As expected, the ZPVE correction is approximately proportional to the magnitude of the interaction energy. Complexes that are more strongly bonded exhibit higher frequency intermolecular vibrational modes and more perturbed intramolecular vibrational modes than weakly bonded complexes. We find the enthalpy of formation $\left[\Delta_{f} H(298 \mathrm{~K})\right]$ to be most negative for $\mathrm{H}_{2} \mathrm{O}-\mathrm{NH}_{3}$, followed by $\mathrm{H}_{2} \mathrm{O}-\mathrm{H}_{2} \mathrm{O}, \mathrm{H}_{2} \mathrm{O}-\mathrm{H}_{2} \mathrm{~S}$, and $\mathrm{H}_{2} \mathrm{O}-\mathrm{PH}_{3}$. The entropy of formation $\left[T \Delta_{f} S(298 \mathrm{~K})\right]$ for $\mathrm{H}_{2} \mathrm{O}-\mathrm{H}_{2} \mathrm{O}$ and $\mathrm{H}_{2} \mathrm{O}-\mathrm{H}_{2} \mathrm{~S}$ is approximately $1 \mathrm{kcal} \mathrm{mol}^{-1}$ larger than for $\mathrm{H}_{2} \mathrm{O}-\mathrm{NH}_{3}$ and $\mathrm{H}_{2} \mathrm{O}-\mathrm{PH}_{3}$. Consequently, the change in the Gibbs free energy $\left[\Delta_{f} G(298 \mathrm{~K})\right]$ is smallest for $\mathrm{H}_{2} \mathrm{O}-\mathrm{NH}_{3}$, followed by $\mathrm{H}_{2} \mathrm{O}-\mathrm{H}_{2} \mathrm{O}, \mathrm{H}_{2} \mathrm{O}-\mathrm{PH}_{3}$, and $\mathrm{H}_{2} \mathrm{O}-\mathrm{H}_{2} \mathrm{~S}$. The effect of the smaller entropy change in the formation of $\mathrm{H}_{2} \mathrm{O}-\mathrm{PH}_{3}$ as compared to $\mathrm{H}_{2} \mathrm{O}-\mathrm{H}_{2} \mathrm{~S}$ is the primary reason for the change in the order of the Gibbs free energy of these two complexes.

While the four complexes exhibit raw interaction energies that differ by a factor of 2 , the equilibrium constants of formation $\left[k_{\mathrm{eq}}(298 \mathrm{~K})\right]$ span more than two orders of magnitude. The laboratory work of Glindermann et $a l^{44}$ found that $\mathrm{PH}_{3}$ was much less readily absorbed into water aerosol than $\mathrm{H}_{2} \mathrm{~S}$ or $\mathrm{NH}_{3}$. We can consider the $\mathrm{H}_{2} \mathrm{O}-\mathrm{H}_{2} \mathrm{~S}$, $\mathrm{H}_{2} \mathrm{O}-\mathrm{NH}_{3}$, and $\mathrm{H}_{2} \mathrm{O}-\mathrm{PH}_{3}$ complexes to be simple models for this aerosol incorporation process. Our current results would indicate that $\mathrm{NH}_{3}$ is certainly much more readily incorporated than $\mathrm{H}_{2} \mathrm{~S}$ or $\mathrm{PH}_{3}$, as it has an appreciably larger interaction energy and equilibrium constant of formation. However, the interaction energy of $\mathrm{H}_{2} \mathrm{O}-\mathrm{H}_{2} \mathrm{~S}$ is only slightly larger than that of $\mathrm{H}_{2} \mathrm{O}-\mathrm{PH}_{3}$ and the equilibrium constant of formation of $\mathrm{H}_{2} \mathrm{O}-\mathrm{PH}_{3}$ is actually slightly higher than that of $\mathrm{H}_{2} \mathrm{O}-\mathrm{H}_{2} \mathrm{~S}$. Hence, it appears that the $\mathrm{H}_{2} \mathrm{O}-\mathrm{H}_{2} \mathrm{~S}, \mathrm{H}_{2} \mathrm{O}$ $-\mathrm{NH}_{3}$, and $\mathrm{H}_{2} \mathrm{O}-\mathrm{PH}_{3}$ monohydrated dimers are not an adequate model for the incorporation of $\mathrm{H}_{2} \mathrm{~S}, \mathrm{NH}_{3}$, and $\mathrm{PH}_{3}$ into aerosol. At a macroscopic level, $\mathrm{H}_{2} \mathrm{~S}$ gas is an order of magnitude more soluble in liquid water than $\mathrm{PH}_{3}$ gas at atmospherically relevant temperatures with $\mathrm{NH}_{3}$ more than three orders of magnitude more soluble. ${ }^{74}$ These experimental aqueous solubilities somewhat corroborate the work of
Glindermann et al. ${ }^{44}$ However, we suggest that molecular dynamics simulations including many water molecules and other aerosol substituents are necessary to properly understand the mobility of $\mathrm{H}_{2} \mathrm{~S}, \mathrm{NH}_{3}$, and $\mathrm{PH}_{3}$ in the atmosphere. Our current $a b$ initio calculations of $\mathrm{H}_{2} \mathrm{O}-\mathrm{H}_{2} \mathrm{O}, \mathrm{H}_{2} \mathrm{O}-\mathrm{H}_{2} \mathrm{~S}$, $\mathrm{H}_{2} \mathrm{O}-\mathrm{NH}_{3}$, and $\mathrm{H}_{2} \mathrm{O}-\mathrm{PH}_{3}$ should be useful as a benchmark for calibrating subsequent molecular dynamics models.

\section{CONCLUSIONS}

We have calculated optimized geometries, harmonic vibrational frequencies, and interaction energies for $\mathrm{H}_{2} \mathrm{O}-\mathrm{H}_{2} \mathrm{O}, \mathrm{H}_{2} \mathrm{O}-\mathrm{H}_{2} \mathrm{~S}, \mathrm{H}_{2} \mathrm{O}-\mathrm{NH}_{3}, \mathrm{H}_{2} \mathrm{O}-\mathrm{PH}_{3}$, and their constituent monomers with conventional $\mathrm{CCSD}(\mathrm{T})$ theory and the newly developed explicitly correlated CCSD(T)-F12 method. We find that geometric parameters of $\mathrm{H}_{2} \mathrm{O}, \mathrm{H}_{2} \mathrm{~S}$, $\mathrm{NH}_{3}$, and $\mathrm{PH}_{3}$ monomers calculated with the CCSD(T)-F12 methods are in impressive agreement with the experiment and with results obtained using much larger basis sets using conventional $\operatorname{CCSD}(\mathrm{T})$ theory.

For the hydrated complexes, we find that the explicitly correlated CCSD(T)-F12 methods perform very well in calculating intermolecular distances and deliver interaction energies that are in close agreement with the CCSD(T)/CBS limit. There is no significant difference in the results obtained with either the $\operatorname{CCSD}(\mathrm{T})-\mathrm{F} 12 \mathrm{a}$ or $\operatorname{CCSD}(\mathrm{T})-\mathrm{F} 12 \mathrm{~b}$ methods. In general, we find that $\operatorname{CCSD}(\mathrm{T})-\mathrm{F} 12$ interaction energies obtained with the VTZ-F12 basis set are in better agreement with the $\operatorname{CCSD}(\mathrm{T}) / \mathrm{CBS}$ limit than conventional $\operatorname{CCSD}(\mathrm{T})$ results obtained with the AV5Z basis set.

We have also investigated two different ways to reduce the effects of BSSE with conventional CCSD(T), namely, the popular $\mathrm{CP}$ correction and limiting diffuse basis functions to the heavy atoms only. We find that for a given cardinal number, these selectively augmented correlation consistent basis sets yield $\operatorname{CCSD}(\mathrm{T})$ results that are closer to the $\operatorname{CCSD}(\mathrm{T}) /$ CBS limit than the corresponding fully augmented basis sets. We find that the difference between the standard $\operatorname{CCSD}(\mathrm{T})$ and $\mathrm{CP}$ corrected $\mathrm{CCSD}(\mathrm{T})$ interaction energies and intermolecular distances is significantly reduced with the selectively augmented basis sets as compared to the fully augmented basis sets. This indicates that for the complexes considered, BSSE is appreciably smaller when diffuse basis functions are restricted to the heavy atoms only. We suggest that when using the $\operatorname{CCSD}(\mathrm{T})$ method, a careful selection of diffuse basis functions can significantly reduce BSSE, avoiding the need for computationally expensive CP correction.

\section{ACKNOWLEDGMENTS}

We acknowledge Pavel Hobza, Janet del Bene, Daryl Howard, and Lauri Halonen for helpful discussions. We acknowledge the Marsden Fund administered by the Royal Society of New Zealand for financial support.

\footnotetext{
${ }^{1}$ V. Vaida and J. E. Headrick, J. Phys. Chem. A 104, 5401 (2000).

${ }^{2}$ V. Vaida, J. S. Daniel, H. G. Kjaergaard, L. M. Goss, and A. F. Tuck, Q. J. R. Meteorol. Soc. 127, 1627 (2001)

${ }^{3}$ V. Vaida, H. G. Kjaergaard, and K. J. Feierabend, Int. Rev. Phys. Chem. 22, $203(2003)$.

${ }^{4}$ C. E. Kolb, J. T. Jayne, D. R. Worsnop, M. J. Molina, R. F. Meads, and
} 
A. A. Viggiano, J. Am. Chem. Soc. 116, 10314 (1994).

${ }^{5}$ K. Morokuma and C. Muguruma, J. Am. Chem. Soc. 116, 10316 (1994)

${ }^{6}$ G. J. Frost and V. Vaida, J. Geophys. Res., [Atmos.] 100, 18803, DOI:10.1029/95JD01940 (1995).

${ }^{7}$ F. Huisken, M. Kaloudis, and A. Kulcke, J. Chem. Phys. 104, 17 (1996).

${ }^{8}$ G. R. Low and H. G. Kjaergaard, J. Chem. Phys. 110, 9104 (1999).

${ }^{9}$ S. Aloisio and J. S. Francisco, Acc. Chem. Res. 33, 825 (2000).

${ }^{10}$ J. C. Hansen and J. S. Francisco, ChemPhysChem 3, 833 (2002).

${ }^{11}$ S. S. Xantheas and T. H. J. Dunning, J. Chem. Phys. 99, 8774 (1993).

${ }^{12}$ J. O. Jung and R. B. Gerber, J. Chem. Phys. 105, 10332 (1996).

${ }^{13}$ W. Klopper, J. G. C. M. van Duijneveldt-van de Rijdt, and F. B. van Duijneveldt, Phys. Chem. Chem. Phys. 2, 2227 (2000).

${ }^{14}$ X. Huang, B. J. Braams, and J. M. Bowman, J. Phys. Chem. A 110, 445 (2006).

${ }^{15}$ H. G. Kjaergaard, A. L. Garden, G. Chaban, R. B. Gerber, D. A. Matthews, and J. F. Stanton, J. Phys. Chem. A 112, 4324 (2008).

${ }^{16}$ S. K. Min, C. L. Eun, H. M. Lee, D. Y. Kim, and K. S. Kim, J. Comput. Chem. 29, 1208 (2008).

${ }^{17}$ T. Salmi, V. Hänninen, A. L. Garden, H. G. Kjaergaard, J. Tennyson, and L. Halonen, J. Phys. Chem. A 112, 6305 (2008).

${ }^{18}$ G. Köhler and R. Janoschek, J. Phys. Chem. 91, 2051 (1987)

${ }^{19}$ Z. Latajka and S. Scheiner, J. Phys. Chem. 94, 217 (1990).

${ }^{20}$ J. Sadlej, R. Moszynski, J. C. Dobrowolski, and A. P. Mazurek, J. Phys. Chem. A 103, 8528 (1999).

${ }^{21}$ N. A. Zvereva, Atmos. Oceanic Opt. 16, 203 (2003).

${ }^{22}$ I. Bandyopadhyay, H. M. Lee, and K. S. Kim, J. Phys. Chem. A 109, 1720 (2005).

${ }^{23}$ J. R. Lane and H. G. Kjaergaard, J. Chem. Phys. 128, 034302 (2008).

${ }^{24}$ R. D. Amos, Chem. Phys. 104, 145 (1986).

${ }^{25}$ W.-B. Wang, F.-M. Tao, and Y.-K. Pan, Chem. Phys. Lett. 230, 480 (1994).

${ }^{26}$ A. Vibòk, G. Halász, and I. Mayer, Mol. Phys. 93, 873 (1998)

${ }^{27}$ W.-Z. Wang, X.-M. Pu, W.-X. Zheng, N.-B. Wong, and A.-M. Tian, Chin. J. Chem. 21, 1586 (2003).

${ }^{28}$ D. P. Tew, W. Klopper, C. Neiss, and C. Hättig, Phys. Chem. Chem Phys. 9, 1921 (2007)

${ }^{29}$ A. Halkier, W. Klopper, T. Helgaker, P. Jørgensen, and P. R. Taylor, J. Chem. Phys. 111, 9157 (1999).

${ }^{30}$ O. Marchetti and H.-J. Werner, Phys. Chem. Chem. Phys. 10, 3400 (2008).

${ }^{31}$ A. Halkier, H. Koch, P. Jørgensen, O. Christiansen, I. M. B. Nielsen, and T. Helgaker, Theor. Chem. Acc. 97, 150 (1997).

${ }^{32}$ S. Simon, M. Duran, and J. J. Dannenberg, J. Chem. Phys. 105, 11024 (1996).

${ }^{33}$ A. L. Garden, J. R. Lane, and H. G. Kjaergaard, J. Chem. Phys. 125, 144317 (2006).

${ }^{34}$ S. F. Boys and F. Bernardi, Mol. Phys. 19, 553 (1970).

${ }^{35}$ P. Hobza and Z. Havlas, Theor. Chem. Acc. 99, 372 (1998).

${ }^{36}$ S. Simon, J. Bertran, and M. Sodupe, J. Phys. Chem. A 105, 4359 (2001).

${ }^{37}$ J. Demaison and J. Lievin, Mol. Phys. 106, 1249 (2008).

${ }^{38}$ C. K. Kim, H. Zhang, S. H. Yoon, J. Won, M. J. Lee, and C. K. Kim, J. Phys. Chem. A 113, 513 (2009).

${ }^{39}$ S. Simon, M. Duran, and J. J. Dannenberg, J. Phys. Chem. A 103, 1640 (1999).

${ }^{40}$ A. D. Boese, J. M. L. Martin, and W. Klopper, J. Phys. Chem. A 111, 11122 (2007).

${ }^{41}$ D. B. Cook, J. A. Sordo, and T. L. Sordo, Int. J. Quantum Chem. 48, 375 (1993)

${ }^{42}$ R. Wieczorek, L. Haskamp, and J. J. Dannenberg, J. Phys. Chem. A 108, 6713 (2004)

${ }^{43}$ Y. Zhao and D. G. Truhlar, J. Phys. Chem. A 110, 5121 (2006).

${ }^{44}$ D. Glindemann, M. Edwards, and P. Kuschk, Atmos. Environ. 37, 2429
(2003).

${ }^{45}$ See EPAPS supplementary material at http://dx.doi.org/10.1063/ 1.3159672 for the full optimized geometries and harmonic frequencies of $\mathrm{H}_{2} \mathrm{O}-\mathrm{H}_{2} \mathrm{O}, \mathrm{H}_{2} \mathrm{O}-\mathrm{H}_{2} \mathrm{~S}, \mathrm{H}_{2} \mathrm{O}-\mathrm{NH}_{3}$, and $\mathrm{H}_{2} \mathrm{O}-\mathrm{PH}_{3}$ obtained with the explicitly correlated $\mathrm{CCSD}(\mathrm{T})-\mathrm{F} 12$ methods and the full optimized geometries of $\mathrm{H}_{2} \mathrm{O}-\mathrm{H}_{2} \mathrm{O}, \mathrm{H}_{2} \mathrm{O}-\mathrm{H}_{2} \mathrm{~S}, \mathrm{H}_{2} \mathrm{O}-\mathrm{NH}_{3}$, and $\mathrm{H}_{2} \mathrm{O}-\mathrm{PH}_{3}$ obtained with conventional $\operatorname{CCSD}(\mathrm{T})$

${ }^{46}$ T. Helgaker, T. A. Ruden, P. Jørgensen, J. Olsen, and W. Klopper, J. Phys. Org. Chem. 17, 913 (2004).

${ }^{47}$ T. Helgaker, J. Gauss, P. Jørgensen, and J. Olsen, J. Chem. Phys. 106, 6430 (1997).

${ }^{48}$ T. H. Dunning, Jr., J. Chem. Phys. 90, 1007 (1989).

${ }^{49}$ A. K. Wilson and T. H. Dunning, Jr., J. Chem. Phys. 119, 11712 (2003).

${ }^{50}$ T. H. Dunning, Jr., K. A. Peterson, and A. K. Wilson, J. Chem. Phys. 114, 9244 (2001).

${ }^{51}$ D. P. Schofield, J. R. Lane, and H. G. Kjaergaard, J. Phys. Chem. A 111, 567 (2007).

${ }^{52}$ MOLPRO, a package of ab initio programs designed by H.-J. Werner and P. J. Knowles, Version 2008.1, R. Lindh, F. R. Manby, M. Schütz et al.

${ }^{53}$ G. Adler, T. B. Knizia, and H.-J. Werner, J. Chem. Phys. 127, 221106 (2007).

${ }^{54}$ K. A. Peterson, T. B. Adler, and H.-J. Werner, J. Chem. Phys. 128, 084102 (2008).

${ }^{55}$ F. R. Manby, J. Chem. Phys. 119, 4607 (2003).

${ }^{56}$ H.-J. Werner, T. B. Adler, and F. R. Manby, J. Chem. Phys. 126, 164102 (2007).

${ }^{57}$ F. Weigend, A. Köhn, and C. Hättig, J. Chem. Phys. 116, 3175 (2002).

${ }^{58}$ F. Weigend, Phys. Chem. Chem. Phys. 4, 4285 (2002).

${ }^{59}$ K. E. Yousaf and K. A. Peterson, J. Chem. Phys. 129, 184108 (2008).

${ }^{60}$ T. Helgaker, P. Jørgensen, and J. Olsen, Molecular Electronic Structure Theory (Wiley, New York, 2000).

${ }^{61}$ A. Halkier, T. Helgaker, P. Jørgensen, W. Klopper, H. Koch, J. Olsen, and A. K. Wilson, Chem. Phys. Lett. 286, 243 (1998).

${ }^{62} \mathrm{~J}$. Olsen, private communication $(01 / 11 / 2002)$.

${ }^{63}$ D. A. McQuarrie, Statistical Mechanics (University Science Books, Sausalito, 2000)

${ }^{64}$ M. D. Harmony, V. W. Laurie, R. L. Kuczkowski, D. A. Ramsay, F. J. Lovas, W. J. Lafferty, and A. G. Maki, J. Phys. Chem. Ref. Data 8, 619 (1979).

${ }^{65}$ G. Rauhut, G. Knizia, and H.-J. Werner, J. Chem. Phys. 130, 054105 (2009).

${ }^{66}$ P. A. Stockman, R. E. Bumgarner, S. Suzuki, and G. A. Blake, J. Chem. Phys. 96, 2496 (1992).

${ }^{67}$ J. A. Odutola and T. R. Dyke, J. Chem. Phys. 72, 5062 (1980).

${ }^{68}$ J. F. Stanton, J. Gauss, J. D. Watts, P. G. Szalay, R. J. Bartlett with contributions from A. A. Auer, D. B. Bernholdt, O. Christiansen, M. E. Harding, M. Heckert, O. Heun, C. Huber, D. Jonsson, J. Jusélius, W. J. Lauderdale, T. Metzroth, C. Michauk, D. P. O’Neill, D. R. Price, K. Ruud, F. Schiffmann, A. Tajti, M. E. Varner, J. Vázquez, and the integral packages molecule (J. Almlöf and P. R. Taylor), PROPS (P. R. Taylor), and ABAcus (T. Helgaker, H. J. Aa. Jensen, P. Jørgensen, and J. Olsen). For current version, see http://www.aces2.de.

${ }^{69}$ C. Leforestier, private communication (04/29/2009).

${ }^{70}$ W. Cencek, K. Szalewicz, C. Leforestier, and R. van Harrevelt, J. Chem. Chem. Phys. 10, 4716 (2008).

${ }^{71}$ N. Goldman, R. S. Fellers, C. Leforestier, and R. J. Saykally, J. Phys. Chem. A 105, 516 (2001).

${ }^{72}$ N. Goldman, C. Leforestier, and R. J. Saykally, J. Phys. Chem. A 108, 787 (2004).

${ }^{73}$ Y. Scribano, N. Goldman, R. J. Saykally, and C. Leforestier, J. Phys. Chem. A 110, 5411 (2006).

${ }^{74}$ CRC Handbook of Chemistry and Physics, 88th ed. (CRC, Cleveland, 2007). 